\title{
Spatio-temporal analysis of milk production in Karnataka State
}

\author{
Khalandar $\mathbf{S}^{1}$, M Sivaram $^{2}$, PK Dixit ${ }^{2}$ and Shweta Bijla ${ }^{3}$
}

Received: 27 June 2019 / Accepted: 21 August 2019 / Published online: 28 October 2019

(C) Indian Dairy Association (India) 2019

\begin{abstract}
Among the Indian States, Karnataka State ranks $11^{\text {th }}$ in milk production with 5.7 million tonnes in the year 2017 . However, the milk productivity in Karnataka has been lower than the national average. In this study, region-wise trends in milk production, cattle and buffalo population and their herd efficiency ratio (HER) and average milk yield were analysed. Data on bovine population, animal in milk, milk yield and milk production has been collected and compiled at district level for the period 1997 to 2012. The districts were grouped into different regions and region-wise trend analysis was performed. During the period 2007 to 2011 , the milk production from indigenous cattle, crossbred cattle and buffalo increased by 2.28 per cent, 7.30 per cent and 3.85 per cent respectively.However, the population of indigenous cattle and buffalo have declined. The increased milk production in the state was mainly due to shift to crossbred dairy animals, significant improvement in HER and average milk of the dairy animals across regions. Though the productivity of the bovine population in Karnataka has been increasing, still it is lower than the national average. Therefore, the required strategies and programmes should be augmented for improving productivity.The results reveal that of late the farmers in north region are increasingly adopting crossbred due to its economic efficiency
\end{abstract}

\footnotetext{
${ }^{1}$ Department of Forestry, Dr. YS Parmar, University of Horticulture and Forestry, Nauni, Solan, Himachal Pradesh, India

${ }^{2}$ Division of Dairy Economics, Statistics and Management, South Regional Station, ICAR- National Dairy Research Institute, Adugodi, Bangalore, India

${ }^{3}$ Dairy Economics, Statistics and Management, ICAR- National Dairy
Research Institute, Karnal-132001, Haryana, India

Khalandar S $(\square)$

Department of Forestry, Dr. YS Parmar, University of Horticulture and Forestry, Nauni, Solan, Himachal Pradesh, India

Email:khalandar25s@gmail.com
}

and therefore the favourable conditions including required infrastructure facilities and market access should be created for promoting crossbred in north region for the benefit of the farmers.

Keywords: Buffalo, Crossbred, Herd efficiency ratio, Indigenous, Milk productivity

\section{Introduction}

In India, dairying has become an important secondary source of income for millions of rural families and has assumed the most important role in providing employment and income generating opportunities particularly for small, marginal and women farmers.India ranks first amongst the countries of world in milk production and bovine population. Milk production in India in 2014-15 was 146.3 million tonne (DAHDH, 2016; MoF, 2016). With an annual production of 5.7 million tonnes in the year 2017, Karnataka State ranks 11th in milk production in the country. As per $19^{\text {th }}$ Livestock Census conducted in 2012 (DAH \& VS, 19972015), the total cattle population of Karnataka is about 9.5 million and the buffalo population is about 3.4 million. The important indigenous breeds of Karnataka include Amritmahal, Deoni, Hallikar, Khilari, Krishna valley and MalnadGidda. Holstein Friesian and Jersey of crossbred and Pandharpuri of buffalo are dominated in Karnataka.

There could be number of factors which contributed to increasing trends in milk production. The factors included improvement in milk yield, shift in composition of dairy herd(Arya and Rawat, 1990; Shah and Dave, 2004; Kumar et al., 2013), herd efficiency ratio (Chand and Raju, 2008), better management of animal stock, improved market access, increasing urbanization and farm mechanization, improved access to groundwater irrigation, crops diversification, expansion of veterinary facilities and artificial insemination centers, increasing smallholder dairy production systems, development of road network, setting up of cooperatives, expansion of milk processing and milk collection facility, rising income, per capita income and rise in milk prices (Birthal and Rao, 2004; Kishore et al., 2016). The above review shows that the studies on dynamics of milk production trends are very much limited. The available secondary data are not adequately exploited to bring in linkages among the factors 
affecting milk production trends. In the above backdrop, an attempt was made to analyze the trends in the composition of cattle and buffalo population across the regions of Karnataka State and to assess the role of herd efficiency and productivity on milk production trends.

\section{Materials and Methods}

\section{Data sets used and data sources}

Administrative district level data on bovine population, animal in milk, milk yield and milk production were collected for the period 1997 to 2012 covering four livestock census and integrated sample surveys conducted by the Department of Animal Husbandry and Dairying of Karnataka State (DAH\&VS, $1997-$ 2015). The spatial unit for the analysis was districts which were subsequently grouped into regions (Table 1). The time period considered for the analysis is 1997-98 to 2011-12.

The cluster analysis was used to group districts into three regions viz., Northern, Southern and Coastal and Malnad based on the animal density (number of animals per sq $\mathrm{km}$ ) of indigenous, crossbred and buffalo .

\section{Study variables}

In this study, we focused on analysing trends in milk production in relation to trends in bovine population, herd efficiency ratio (HER) and productivity. HER was worked out as ratio of in-milk population to total bovine population. This is taken as a measure of quality of herds. The higher this ratio, lower the share of unproductive animals and higher milk output. Average milk yield is milk yield per animal per day $(\mathrm{kg})$, a measure of productivity of the animals.

\section{Statistical analysis}

The data on milk production and factors affecting it are not available for all the years. For example, data on bovine population is available for every five years. Therefore, in order to link HER and milk yield with milk production harmonization of data was necessitated. For this purpose, linear interpolation was employed.

The formula used is as follows:

If the known values are $y_{1}$ and $y_{2}$ and, then the $y$ value for some point $x$ can be given as:

$y=y_{1}+\left(x-x_{1}\right)\left(y_{2}-y_{1}\right) /\left(x_{2}-x_{1}\right)$

Where,

xl : $\quad$ Initial year

$\begin{array}{lll}\mathrm{x} 2 & : & \text { End year } \\ \mathrm{y} 1 & : & \text { Initial year value } \\ \text { y2 } & : & \text { End year value }\end{array}$

Sometimes, it was needed to extrapolate missing values for a few variables in time for certain years using available data. In that case future value was estimated using the following formula:

$A=P(1+r)^{2}$

Where,

$\begin{array}{lll}\text { A } & : & \text { Future Value } \\ \mathrm{P} & : & \text { Initial Value } \\ \mathrm{r} & : & \text { Compound Annual Growth Rate } \\ \mathrm{t} & : & \text { time horizon }\end{array}$

In order to analyze the trends in milk production, bovine population and milk yield the Compound Annual Growth Rates (CAGR) were worked out. The formulae is

$$
\text { CAGR }=\frac{\text { (Value of variable in eding year }- \text { value of voriable in initial year) }}{\text { Value of voriable inst artingyear } \times \text { number of yoars }} \times 100
$$

Where, CAGR is Compound Annual Growth Rate

\section{Results and Discussion}

\section{Milk production trends across different regions of Karnataka}

The milk production in the state increased from 3948 ('000 MT) in 1997 to 6200 ('000 MT) in 2015 by 57.04 per cent (Fig. 1). Of the total milk production, the contribution of indigenous breed decreased from 40 per cent in 1997 to 22 per cent in 2015. In contrast, the contribution of crossbred increased significantly from 23 per cent in 1997 to 48 per cent in 2015. The contribution of milk production from buffalo in 1997 was 37 per cent and it decreased to 30 per cent in 2015. The increasing share of milk production from crossbred could largely to be attributed to increasing adoption of crossbred animals due to higher productivity. Further, the changing farm practices from manual to mechanization might have led to decreasing indigenous cattle thereby reducing share of milk production from indigenous breed to total milk production. This reason may also apply to some extent, for decreasing contribution of milk production from buffalos. 


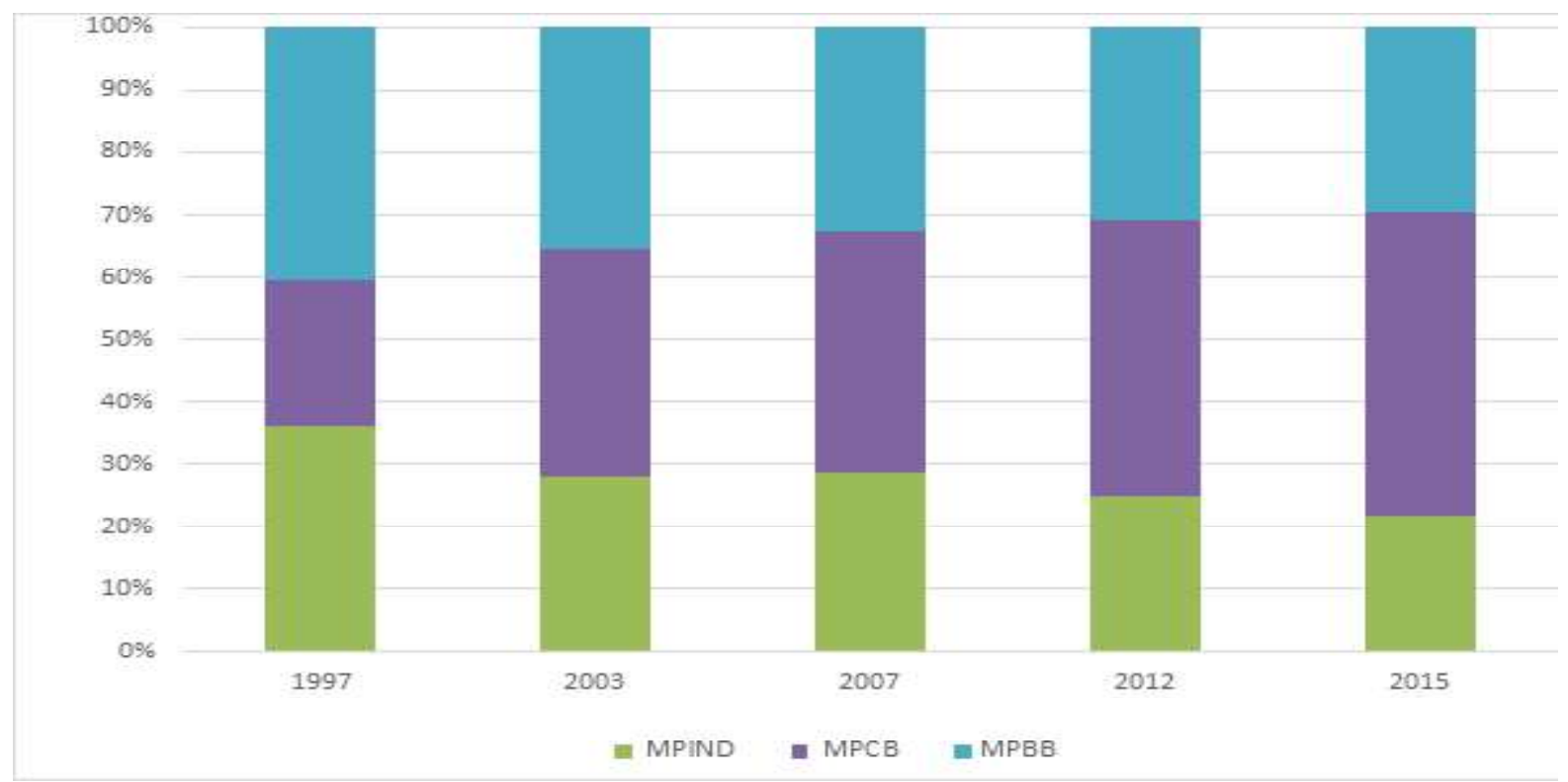

Fig. 1Changing scenario of milk production in Karnataka State

Table 1 List of districts under each region obtained using cluster analysis

\begin{tabular}{ll}
\hline Region & Districts \\
\hline North & Belagavi, Ballari, Bidar, Vijayapura, Dharwad, Kalaburagi, \\
& Raichur, Bagalkote, Gadag, Haveri, Koppal, Yadgiri \\
South & Bengaluru (U), Bengaluru ( R), Chitradurga, Hassan, Kolar, \\
& Mandya, Mysuru, Tumakuru, Davanagere, Ramanagara, Chikkaballapura \\
Malnad and & Chikmagalur, Dakshina Kannada, Kodagu, Shivamogga, Uttara \\
Coastal & Kannada, Chamarajnagra, Udupi (7 Nos.) \\
\hline
\end{tabular}

\section{Indigenous}

The milk production from indigenous breed in Karnataka decreased from 1427 (000 MT) in 1997 to 1070 ('000 MT) in 2001 by CAGR of 3.58 per cent (Table 2). Thereafter, there was a steep rise in milk production up to 2011 with the positive CAGR of 2.28 per cent. The milk production from indigenous breed in northern region of Karnataka declined from 591 ('000 MT) in 1997 to 468 ('000 MT) in 2001 by CAGR of 3.25 per cent. Thereafter, it increased with the positive CAGR of 4.1 per cent. The milk production from indigenous breed in southern region decreased from 568 ('000 MT) in 1997 to 317 ('000 MT) in 2001 by CAGR 6.7 per cent, thereafter the growth rate witnessed 1.73 per cent rise. The milk production from indigenous breed in Malnad and Coastal region of Karnataka increased from 268 ('000 MT) in 1997 to 339 ('000 MT) in 2001 by CAGR of 1.13 per cent. From 2001 onwards there was a marginal decline. The milk production from indigenous breed has decreased from 1997 to 2003. This might be becauseof severedrought that occurred during the period 2002 to 2003 which led to reduced crop production and inadequate availability of feed and fodder. The reasons for increased milk production might be due to better management practices, increase in herd efficiency ratio etc.The variation in the milk production across regions can be ascribed to the changing population dynamics.

\section{Crossbred}

The milk production from crossbred in Karnataka increased significantly from 920 ('000 MT) in 1997 to 2515 ('000 MT) in 2011 with the average growth rate of 5.74 per cent (Table 2). The milk production from crossbred in northern region of Karnataka increased from 72 ('000 MT) in 1997 to 360 ('000 MT) in 2011 with the average growth rate of 11 per cent. The milk production from crossbred in southern region ofKarnataka increased from 750 ('000 MT) in 1997 to 1642 ('000 MT) in 2012 with the average growth rate of 4.38 per cent. The milk production from crossbred in Malnad and Coastal region of Karnataka increased from 98 ('000 MT) in 1997 to 513 ('000 MT) in 2012 with the average growth rate of 10.17 per cent. The milk production contribution from crossbred was continuously on a rise because of the advantage of higher productivity of crossbred owing to availability of quality semen for breeding and good management practices etc. The differences in themilk production across regions could be mainly due to the differences in the in-milk population and productivity.

\section{Buffalo}

The milk production from buffalo in Karnataka decreased from 1601 ('000 MT) in 1997 to 1433 ('000 MT) in 2007 by 2.18 per cent 
(Table 2). Thereafter, there was a positive growth from 1381 ('000 MT) in 2007 to 1668 ('000 MT) in 2011 by 3.85 per cent. The milk production from buffalo in northern region of Karnataka wasstable from 1997 to 2001 and the growth rate decreased marginally from 2002 to 2006 by -0.51 per cent. From 2007 to 2012 there was a significant rise in milk production with a CAGR of 4.56 per cent. The milk production in southern region of Karnataka declined from 574 ('000 MT) in 1997 to 450 ('000 MT) in 2001 by 4.75 per cent. From 2002 to 2006 , there was a marginal growth of 0.17 per cent. Since then there was a positive growth rate in milk production from 434 ('000 MT) in 2007 to 513 ('000 MT) in 2012 with a CAGR of 2.75 per cent. The milk production of buffalo in Malnad and Coastal region of Karnataka decreased from 183 ('000 MT) in 1997 to 143 ('000 MT) in 2001 by 2.18 per cent. Thereafter, growth in milk production was stable up to 2006 by CAGR of 0.60 per cent. The notable growth in milk production was observed from 140 ('000 MT) in 2007 to 160 ('000 MT) in 2012 by CAGR of 3.85 per cent.
The decrease in buffalo milk production from 1997 to 2003 might be due to severe drought which led to shortage of feed and fodder affecting milk production besides lowering water availability. The differences in the milk production across regions might largely bedue to the differential in the population levels and productivity levels.

\section{Trends in bovine population across different regions of Karnataka}

Over the years, male to female ratio of the indigenous cattle remained almost unchanged at 1:1.5 across all the regions of Karnataka (Table 3). With regard to crossbred there was a very significant increase in sex ratio in favour of female. However, it widely varied across the regions over the years. In 2011-12, the highest male to female sex ratio was found in southern region of Karnataka. The sex ratio in northern region was about 1:6.5 and 1:8.8 in Malnad and Coastal respectively. Buffalo in northern region had male to female ratio of $1: 9$, where as southern region

Table 2 Growth rates (per cent) in milk production across different regions of Karnataka

\begin{tabular}{|c|c|c|c|c|}
\hline \multirow[t]{2}{*}{ Period } & \multicolumn{3}{|c|}{ Region } & \multirow[b]{2}{*}{ Karnataka } \\
\hline & North & Soutl & Coastal\&Malnad & \\
\hline & & \multicolumn{2}{|c|}{ Indigenous } & \\
\hline $1997-2001$ & -3.25 & -6.74 & 0.83 & -3.58 \\
\hline 2002-2006 & 0.35 & 0.09 & 1.13 & 0.93 \\
\hline \multirow[t]{2}{*}{ 2007-2011 } & 4.1 & 1.73 & -0.094 & 2.28 \\
\hline & & \multicolumn{2}{|c|}{ Crossbred } & \\
\hline 1997-2001 & 13.34 & 2.85 & 19.68 & 6.12 \\
\hline 2002-2006 & 6.32 & 3.24 & 3.94 & 3.76 \\
\hline \multirow[t]{2}{*}{ 2007-2011 } & 8.81 & 7.07 & 6.90 & 7.30 \\
\hline & & \multicolumn{2}{|c|}{ Buffalo } & \\
\hline 1997-2001 & 0.06 & -4.75 & -5.43 & -2.18 \\
\hline 2002-2006 & -0.51 & 0.17 & 0.60 & -0.27 \\
\hline 2007-2011 & 4.56 & 2.75 & 2.19 & 3.85 \\
\hline
\end{tabular}

Table 3 Region-wise trends in sex ratio (Male: Female) of bovine population in Karnataka

\begin{tabular}{llllc}
\hline & \multicolumn{3}{c}{ Indigenous } & \\
\cline { 2 - 5 } Year & Northern & Southern & Malnad\& Coastal & Karnataka \\
\hline 1997 & $1: 0.83$ & $1: 1.28$ & $1 ; 1.48$ & $1: 1.12$ \\
2003 & $1: 0.87$ & $1: 1.26$ & $1: 1.56$ & $1: 1.13$ \\
2007 & $1: 0.96$ & $1: 1.33$ & $1: 1.66$ & $1: 1.20$ \\
2012 & $1: 1.10$ & $1: 1.60$ & $1: 1.93$ & $1: 1.38$ \\
& & Crossbred & & \\
1997 & $1: 3.78$ & $1: 4.01$ & $1: 6.30$ & $1: 4.34$ \\
2003 & $1: 5.18$ & $1: 15.56$ & $1: 6.66$ & $1: 9.74$ \\
2007 & $1: 6.10$ & $1: 16.90$ & $1: 6.70$ & $1: 12.26$ \\
2012 & $1: 6.51$ & $1: 18.65$ & $1: 8.78$ & $1: 5.59$ \\
& & Buffalo & & $1: 7.12$ \\
1997 & $1: 8.25$ & $1: 9.04$ & $1: 1.67$ & $1: 7.66$ \\
2003 & $1: 8.77$ & $1: 11.51$ & $1: 2.32$ & $1: 8.65$ \\
2007 & $1: 8.69$ & $1: 11.18$ & $1: 2.82$ & \\
2012 & $1: 9.43$ & $1: 11.10$ & $1: 3.81$ & \\
\hline
\end{tabular}


has the highest ratio of $1: 11$, and Malnad and Coastal region had least of $1: 3.8$. The male to female ratio in indigenous breed was almost constant because the small and marginal farmers utilize males for their farming operations and rear females for both farm works and milk production.

\section{Indigenous}

The population of indigenous to the total bovine population in Karnataka was 51 per cent of the total bovine population, which is higher as compared to crossbred and buffalo. The population of indigenous cattle in Karnataka decreased from 92.92 lakh in 1997 to 84.43 lakh in 2001 by 1.89 per cent (Table 4). During the period 2002 to 2007 the population was stable. However, the population again decreased from 83.14 lakh in 2007 to 69.46 lakh in 2011 by 3.53 per cent. The indigenous population was highest in northern region of Karnataka. The population decreased from 37.45 lakh in 1997 to 34.59 lakh in 2001 by 1.06 per cent. There was a minimal growth rate from 2002 to 2006 by 1.09 per cent. However, the population declined from 2007 to 2011 by 2.25 per cent. The indigenous population in southern region of Karnataka declined from 32.79 lakh in 1997 to 28.79 lakh in 2001 by 2.5 per cent. However, during 2002 to 2006 there was a positive CAGR of 1.09 per cent. The population decreased from 26.44 lakh in 2007 to 20.40 lakh in 2011 by 5.05 per cent. The indigenous population in Malnad and Coastal region of Karnataka continuously decreased from 22.68 in 1997 to 15.37 in 2011.The decreasing indigenous population was due to increasing adoption of crossbred and changing farming practices from manual to mechanization and shifting to plantation crops. The reason for higher population levels in north might be due to higher use of indigenous cattle in farming as well as milk production.

\section{Crossbred}

The crossbred in Karnataka increased from 12.93 lakh in 1997 to 29.13 in 2011(Table.4). The population of crossbred in northern region of Karnataka increased from 2.39 lakh in 1997 to 4.35 lakh with an average growth rate of 3.62 per cent. The population of crossbred in southern region increased from 7.62 lakh in 1997 to 17.03 lakh with a growth rate of 4.77 per cent. The population of crossbred in Malnad and Coastal region of Karnataka increased from 2.92 lakh in 1997 to 6.30 lakh in 2011 with a growth rate of 4.48 per cent. The reasons for increasing population across all the regions over the period could be mainly because of higher productivity, and focus of farmers on milk production. The higher levels of efficiency of crossbred provide better monetary return for farmers.

\section{Buffalo}

The population of buffalo in Karnataka decreased from 44.03 lakh in 1997 to 41.50 lakh in 2001 by 1.18 per cent (Table 4). While there was a positive marginal growth rate from 2003 to 2006 by 0.80 per cent, a pronounced decrease was found during 2007 to 2011 from 43.29 lakh to 36.42 lakh by 3.40 per cent. The population of buffalo in northern region of Karnataka remained nearly constant. However, the population increased from 2003 to 2006 with CAGR of 2.49 per cent. Since the year 2007 the population decreased from 25.60 lakh in 2007 to 22.05 lakh by 2.94 per cent. In southern region, the population continuously declined from 21.16 lakh in 1997 to 10.51 lakh in 2011. The population of buffalo in Malnad and Coastal region of Karnataka decreased from 7.69 lakh in 1997 to 3.86 lakh in 2011 by 3.95 per cent. The population of buffalo decreased from 1997 to 2003 mainly due to severe drought during the period 2000 to 2003. The decreasing buffalo population could be attributed to increased adoption of crossbred.

\section{Trends in herd efficiency ratio across different regions of Karnataka}

\section{Indigenous}

The HER of indigenous cattle in Karnataka decreased from 0.21 in 1997 to 0.18 in 2001 and thereafter remained constant up to

Table 4 Growth rates in population across different regions of Karnataka

\begin{tabular}{lllll}
\hline Period & \multicolumn{2}{l}{ Region } & Karnataka \\
\cline { 2 - 5 } & Northren & Southhren & Malnad\&Coastal \\
\hline $1997-2001$ & -1.06 & Indigenous & & -1.89 \\
$2002-2006$ & 1.09 & -2.5 & -2.33 & 0.022 \\
$2007-2011$ & -2.25 & -0.92 & -0.62 & -3.53 \\
& & -5.05 & -4.08 & 3.10 \\
$1997-2001$ & -0.70 & Crossbred & & 5.59 \\
$2002-2006$ & 5.84 & 3.22 & 5.55 & 4.78 \\
$2007-2011$ & 5.72 & 5.79 & 5.00 & \\
$1997-2001$ & & 5.30 & 2.89 & -1.18 \\
$2002-2006$ & 0.49 & Buffalo & & 0.80 \\
$2007-2011$ & 2.49 & -4.10 & -3.84 & -3.40 \\
\hline
\end{tabular}


Fig. 1 Species-wise milk yield trends across different regions of Karnataka

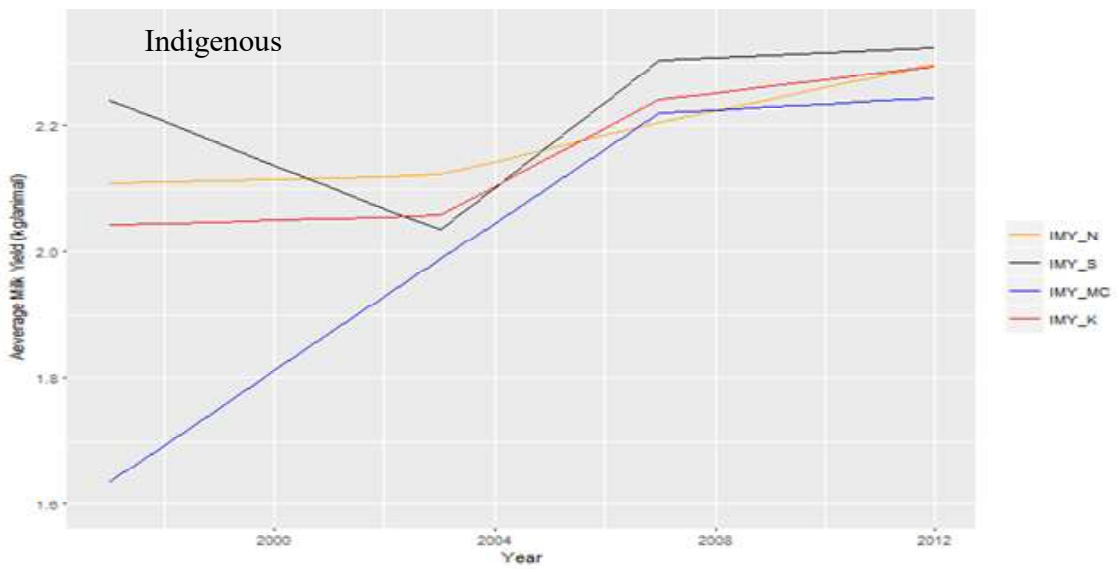

IMY_N > Indigenous milk-yield in northern region; IMY_S > Indigenous milk-yield in southern region; IMY_MC > Indigenous milkyield in malnad and coastal region; IMY_K >Indigenous milk-yield in Karnataka

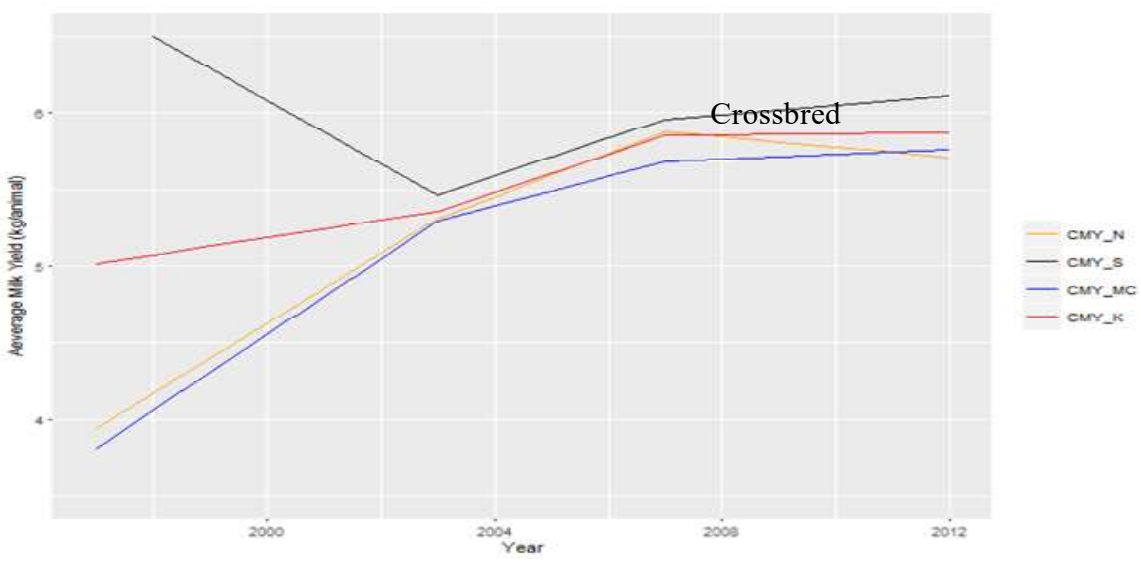

CMY_N $>$ Crossbred milk-yield in northern region; CMY_S $>$ Crossbred milk-yield in southern region; $\quad$ CMY_MC >

Crossbred milk-yield in malnad and coastal region:CMY_K > Crossbred milk-yield in Karnataka;

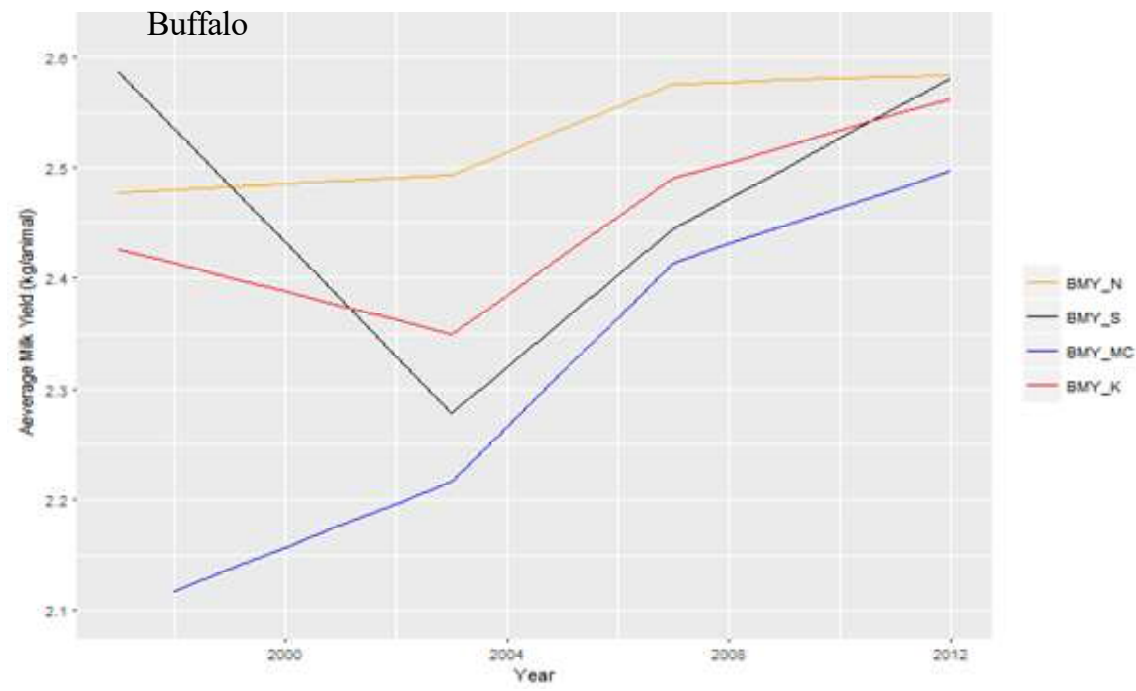

BMY_N > Buffalo milk-yield in northern region; BMY_S > Buffalo milk-yield in southern region; BMY_MC $>$ Buffalo milk-yield in malnad and coastal region;BMY_K $>$ Buffalo milk-yield in Karnataka. 
2007 (Fig. 2.C.). However, the HER increased to 0.25 in 2011.The HER of indigenous in northern region of Karnataka decreased from 0.24 in 1997 to 0.16 in 2007 while, it increased from 0.16 in 2007 to 0.23 in 2011. The HER of indigenous in southern region of Karnataka decreased continuously from 1997 to 2011. HER was higherIn Malnad and Coastal regions of Karnataka,. However, a declining trend was observed during 1997 to 2003, which could be due to severe drought. However, the increasing trend in HER thereafter could be due to improved management practices. The changing farm practices from manual to mechanization could have reduced the number of work animals in the herd.

\section{Crossbred}

The HER of crossbred cattle in Karnataka increased from 0.32 in 1997 to 0.41 in 2001 (Fig. 2.A). Thereafter, it decreased during the period 2002 to 2006 and increased to 0.37 in 2012. The HER of crossbred cattle in northern region of Karnataka marginally increased from 0.33 in 1997 to 0.36 in 2001 and decreased during 2002 to 2006 . However, it increased from 0.32 in 2007 to 0.36 in 2011.The HER in southern region of Karnataka increased from 0.42 in 1997 to 0.46 and remained constant from 2002 to 2006 . However, there was a slight decline from 2007 to 2011. The HER in Malnad and Coastal region of Karnataka decreased from 0.47 in 1997 to 0.32 in 2006 . However it increased during 2007 to 2011. There was no definite trend with respect to crossbred cattle may be that the HER reached its maximum in the state. The observed variations could be due to random effects which generally arise in the process of estimation.

\section{Buffalo}

The HER of buffalo in Karnataka declined from 0.38 in 1997 to 0.35 per cent in 2006 (Fig.2.B). However, HER steeply increased subsequently. The HER in northern region of Karnataka declined from 0.47 in 1997 to 0.35 in 2006. However, HER increased significantly from 2007 to 2011 . The HER of buffalo in southern region of Karnataka decreased from 0.45 in 1997 to 0.38 in 2001. During 2002 to 2011, a steep increase in HER was observed. The HER of buffalo in Malnad and Coastal region of Karnataka decreased from 1997 to 2001. Since then there was a significant increase in HER. The HER in buffalo has been increasing due to improved management practices.

\section{Trends in milk yield trends across different regions of Karnataka}

\section{Indigenous}

The average milk yield from indigenous cattle in Karnataka increasedmarginally from $2.03 \mathrm{~kg}$ in 1997 to $2.04 \mathrm{~kg}$ in 2012, by CAGR of 0.10 per cent (Fig. 3.A). Thereafter, the milk yield increased from 2.04 in 2002 to $2.25 \mathrm{~kg}$ in 2006 by 1.57 per cent. However, the milk yield remained constant during 2007 to 2011. The average milk yield from indigenous breed in northern region of Karnataka increased from $2.06 \mathrm{~kg}$ in 1997 to $2.25 \mathrm{~kg}$ in 2011 by CAGR of 0.45 per cent. The average milk yield from indigenous breed in southern region of Karnataka decreased from $2.23 \mathrm{~kg}$ in 1997 to $2.03 \mathrm{~kg}$ in 2001 by CAGR of 1.25 per cent. During the period 2002 to 2006 there was a positive growth of 1.57 per cent. However, from 2002 to 2006, the milk yield remained almost constant. The average milk yield from indigenous cows in Malnad and Coastal region of Karnataka increased from $1.64 \mathrm{~kg}$ in 1997 to $2.12 \mathrm{~kg}$ in 2006 by 2.51 per cent. Thereafter, it was stabilized. Theincrease in milk yield from indigenous cows might be due tobetter selection of animals and management practices.

\section{Crossbred}

The average milk yield from crossbred in Karnataka increased from $5.1 \mathrm{~kg}$ in 1997 to $5.4 \mathrm{~kg}$ by only 0.90 per cent while it was 1.57 per cent during the period 2002 to 2006 (Fig.3.B). However, the milk yield was almost constant from 2007 to 2011 . The average milk yield from crossbred cattle in northern region of Karnataka increased from $3.9 \mathrm{~kg}$ in 1997 to $5.8 \mathrm{~kg}$ in 2006 by 3.38 per cent. Thereafter, it decreased slightly from 2007 to 2011 by 0.47 per cent. The average milk yield from crossbred cattle in southern region of Karnataka decreased from $6.5 \mathrm{~kg}$ in 1997 to $5.5 \mathrm{~kg}$ in 2001 by CAGR of -2.59 per cent. Thereafter, the growth rate increased from 2002 to 2006 with a CAGR of 0.57 per cent. The milk yield was almost constant from 2007 to 2011 . The average milk yield from crossbred in Malnad and Coastal region of Karnataka increased from $3.7 \mathrm{~kg}$ in 1997 to $5.7 \mathrm{~kg}$ in 2011 by an average growth rate of 3.38 per cent. The milk yield from crossbred hasbeen increasing largely due to better management practices, extension of veterinary facilities and artificial insemination centers.

\section{Buffalo}

Over the years, the milk yield from buffalo in Karnataka decreased slightly from $2.43 \mathrm{~kg}$ in 1997 to $2.35 \mathrm{~kg}$ in 2001 (Fig.3.C). Thereafter, there was a continuous increase in milk yield. The milk yield from buffalo in northern region of Karnataka increased from $2.12 \mathrm{~kg}$ in 1997 to $2.5 \mathrm{~kg}$ in 2011 by CAGR of 0.92 per cent. The milk yield in southern region of Karnataka declined from $2.59 \mathrm{~kg}$ in 1997 to $2.27 \mathrm{~kg}$ in 2001 and thereafter it again increased. The milk yield from buffalo in Malnad and Coastalregions continuously increased from $2.12 \mathrm{~kg}$ in 1997 to $2.5 \mathrm{~kg}$ in 2011 . The milk yield from buffalo has decreased from 1997 to 2003, which might be due to drought.

\section{Conclusions}

Though the indigenous cattle constitute about 51 per cent to the total bovine population in Karnataka its share in milk production is only about 22 per cent. The share of indigenous breed and buffalo to total milk production has been declining. On the other hand, the share of crossbred to total milk production has been 
Fig. 2 Species-wise herd efficiency ratio trends across different regions of Karnataka

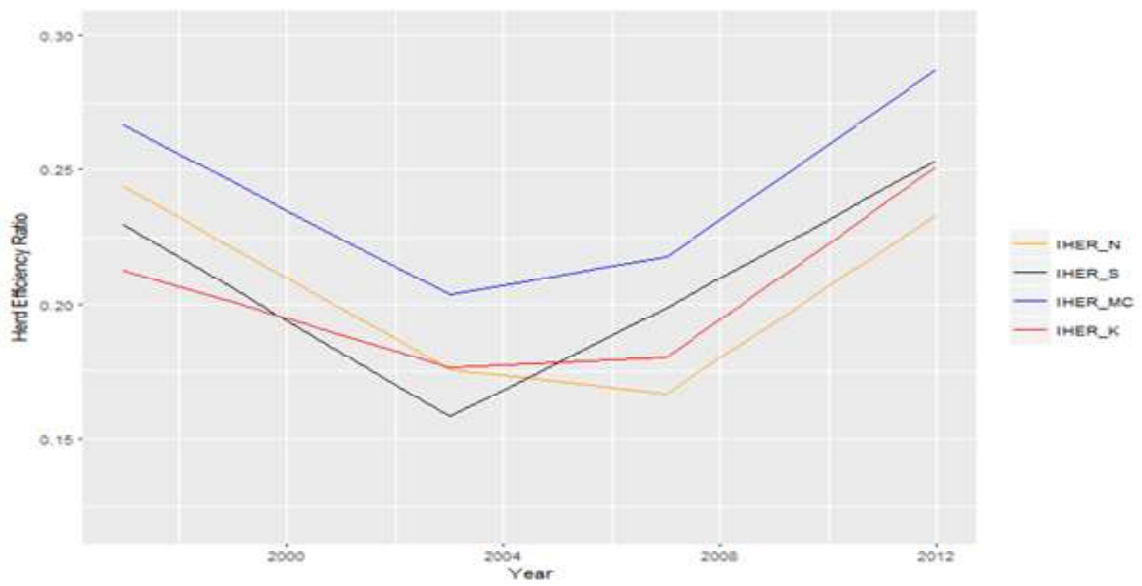

IHER_N > Herd efficiency ratio of indigenous in northern; IHER_S > Herd Efficiency Ratio of indigenous in southern; IHER_MC > Herd efficiency ratio of indigenous in malnad and coastal region; IHER_K $>$ Herd efficiency ratio of indigenous in Karnataka Indigenous

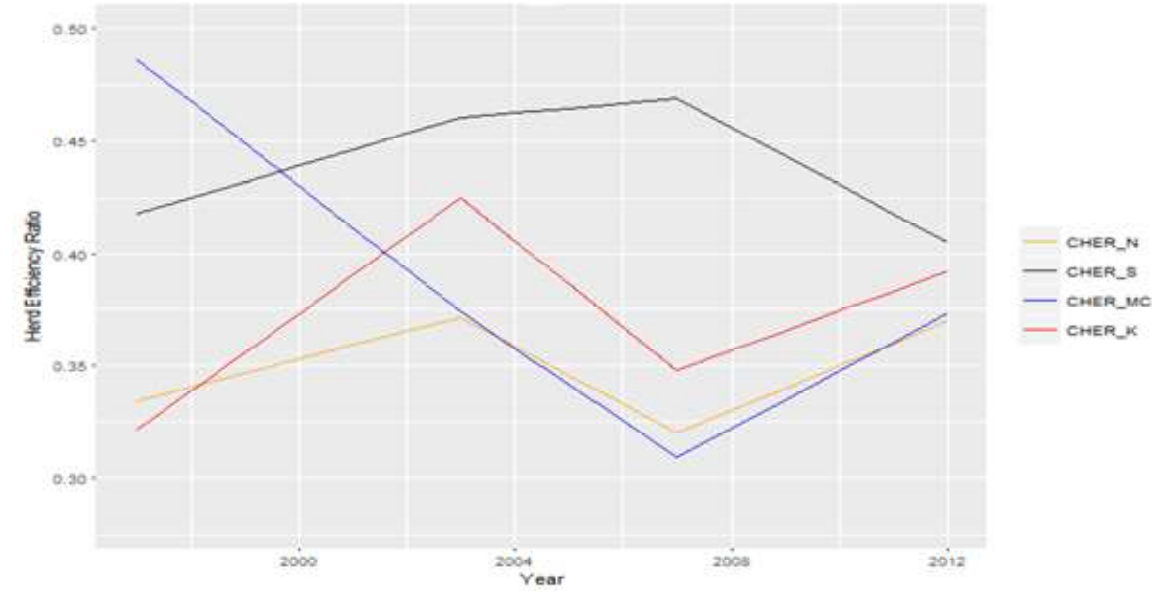

CHER_N $>$ Herd efficiency ratio of crossbred in northern region; CHER _S > Herd efficiency ratio of crossbred in southern region; CHER_MC > Herd efficiency ratio of crossbred in malnad and coastal region: CHER_K > Herd efficiency ratio of crossbred in KarnatakaCrossbred

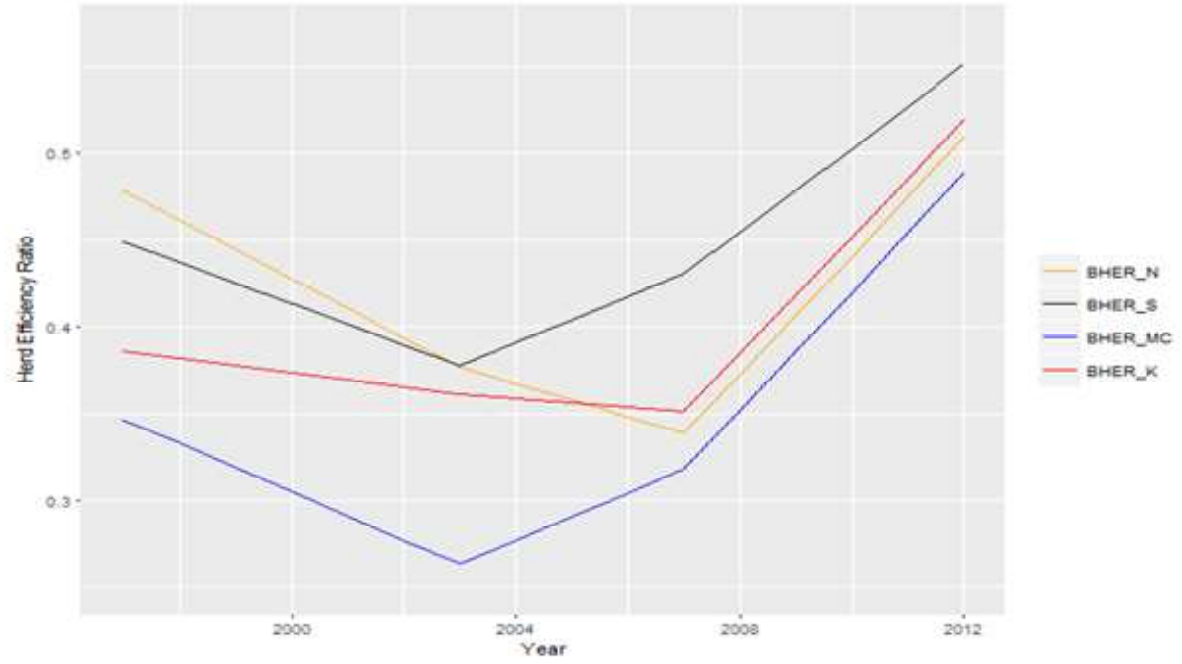

BHER_N $>$ Herd efficiency ratio of buffalo in northern; BHER_S > Herd efficiency ratio of buffalo in southern region; BHER_MC > Herd efficiency ratio of buffalo in malnad and coastal region; BHER_K $>$ Herd efficiency ratio of buffalo in Karnataka

Buffalo 
increasing steadily. Presently, almost half of the milk production in Karantaka state is from crossbred. The indigenous and buffalo population have been on declining trend. On the other hand, the crossbred population in Karnataka increased by about 5 per cent annually mainly due to higher productivity of milk. The shift to crossbred was higher in northern region followed by southern region and Malnad and Coastal region. The trends in HER and milk yield explained higher level of variation in milk production trends for indigenous and crossbred cows and buffalo almost in all the regions. HER and milk yield had a downward trend around 2003 due to drought that prevailed in the state during the period 2000 to 2003. This indicates that the performance of dairying is very much sensitive to drought conditions. The HER among the bovines especially crossbred has been almost stable and any improvement in this area will only marginally increase the milk production. Though the productivity of the bovine population in Karnataka, as indicated by average milk yield has been increasing, still it is lower than the national average. Therefore, the required strategies and programmes should be augmented for improving productivity.The results reveal that of late the farmers in northern region are increasingly adopting crossbred due to its economic efficiency and therefore the required infrastructure facilities and market access should be created for promoting crossbred in northern region for the benefit of the dairy farmers.

\section{Acknowledgements}

This paper is part of the study conducted for partial fulfilment of the Master degree programme in Agricultural Economics of the author from SRS, ICAR-National Dairy Research Institute,
Adugodi, Bangalore. The thesis was submitted in 2017 and the title was "Dynamics of Bovine Population and Milk Production Trends in Karnataka State- an Inter-regional Analysis".

\section{References}

Arya SL, Rawat BS (1990). Growth of milk production in Haryana Statea decomposition analysis. Indian J Dairy Sci 43: 314-318

Birthal PS, Rao PP (2004) Intensification of livestock production in India: Patterns, trends and determinants. Indian J Agric Econ 59: 555-565

Chand R, Raju SS (2008) Livestock sector composition and factors affecting its growth. Indian J Agric Econ 63: 198-210

DAH and VS (1997-2015). Various Reports of Department of Animal Husbandry and Veterinary Services published during 1997-2015. Government of Karnataka.

DAHDH (2016). Annual Report 2015-16. Department of Animal Husbandry, Dairying and Fisheries. Ministry of Agriculture and Farmers Welfare. New Delhi, Government of India.

DES (1997-2015). Various Reports of Department of Economics and Statistics, Directorate of Economics and Statistics, Government of Karnataka.

Kishore A, Birthal PS, Joshi PK, Shah T, Saini A (2016) Patterns and drivers of dairy development in India: Insights from analysis of household and district-level data. Agric Econ Res Rev 29: 1-14

Kumar A, Parappurathu S, Joshi PK (2013) Structural transformation in dairy sector of India. Agric Econ Res Rev 26: 209-220

MoF (2016) Report of the Economic Survey 2015-16. Ministry of Finance, New Delhi, Government of India.

Shah J, Dave D (2010) Regional trends and pattern in milk production and drivers for future growth in Gujarat State. Agric Econ Res Rev 23: 295-302

Sindhu RS, Bhullar AS (2004) Changing structure of farm economy in Punjab: impact of livestock on income and employment. Indian $\mathrm{J}$ Agric Econ 59: 578-587 